Maurizio Cecconi Andrew Rhodes

\section{Pulse pressure: more than 100 years of changes in stroke volume}

Received: 25 January 2011

Accepted: 3 February 2011

Published online: 5 March 2011

(C) Copyright jointly held by Springer and ESICM 2011

This editorial refers to the article available at:

doi:10.1007/s00134-011-2154-z.

M. Cecconi $(\bowtie) \cdot$ A. Rhodes

Department of Intensive Care Medicine,

St George's Healthcare NHS Trust and

St George's University of London,

London SW17 0QT, UK

e-mail: mauriziocecconi@hotmail.com

Tel.: +44-208-7250879

Fax: +44-208-7250879

Arterial pulse pressure (PP) is a variable that is often ignored, despite its ability to provide powerful information. Changes in PP on a beat-to-beat basis reflect changes in the volume of blood ejected from the left ventricle into the arterial conduit of the circulation (stroke volume, SV). Over a longer time interval, the PP can be influenced by vascular tone, but this rarely impacts over the shorter time interval. PP, and therefore techniques that assess changes in the variable (PP analysis, PPA) can therefore be useful adjuncts to a modern monitoring armamentarium for acutely unwell patients.

In 1899 Otto Frank developed the Windkessel (air chambers) model to simulate the interaction between the heart and the circulation [1]. In this model a circuit, in which fluid was pumped in tubes through chambers, simulated the compliance and resistance of the arterial tree. He then suggested that understanding the arterial tone would enable the SV to be determined from the change in pressure. Subsequently, Erlanger and Hooker
(1904) proposed a correlation between SV and change in arterial pressure, suggesting a correlation between cardiac output and arterial PP [2]. It took almost 90 more years before Wesseling developed the first real-time cardiac output monitor based on PPA [3]. The main reason for this delay was that in order to compute real-time data, complex calculations had to be made at a speed too high for the human brain. This issue was solved with the advent of modern computer processing. PPA is now a reality with many monitors being available on the market.

The first studies assessing these new monitors focused on the agreement between cardiac output measured by PPA devices and a so-called gold standard such as Fick's principle or the intermittent thermodilution of the pulmonary artery catheter [4-8]. Whilst the discussion of the validation of PP based cardiac output monitoring devices is beyond the scope of this editorial, we have to stress that the Bland-Altman analysis [9], together with the socalled Critchley percentage error analysis [10], are only appropriate when looking at absolute values of cardiac output, but are of limited use for acute changes. We have recently demonstrated the pitfalls of this approach, demonstrating how the $30 \%$ benchmark is a dogmatic tool based on little evidence [11]. Despite this, a plethora of studies have been published using this approach. According to this flawed analysis many monitors, from oesophageal Doppler to PPA should not be used in clinical practice since their percentage error is greater than $30 \%$ [12]. These results contrast though with studies using these monitors to look at individual changes in SV and guide goal-directed therapy, many of which have resulted in beneficial patient-relevant outcomes [13]. While it is important that any new device is validated against a gold standard, it is more important that a device is introduced into clinical practice with the aim of improving patient outcome, at least providing a guiding tool that would result in better clinical practice than the one that would be based on clinical examination alone [14]. 
Recently more and more authors have described the clinical utility of the "functional haemodynamic" approach as proposed by Pinsky and Payen [15]. New less-invasive devices, based on PPA, have become available, and their ability to track SV in a continuous way allows clinicians to assess the circulation in a dynamic fashion. Without this property the concept of "prediction of fluid responsiveness" may never have been described [16]. In mechanically ventilated patients variations in PP and SV have been demonstrated to be good indicators of fluid responsiveness [17-19]. The limitation of this approach is that the patient has to be completely sedated, in sinus rhythm and ideally with tidal volumes of at least $7 \mathrm{ml} / \mathrm{kg}$ of ideal body weight [20]. This is often applicable in the operating room, but rarely in the ICU where patients are often ventilated in assisted modes maintaining a respiratory drive. For patients not fulfilling the requirements for PP variation and SV variation a different approach altogether has been studied: passive leg raising (PLR) [21].

Dufour et al. [22], in their paper in this issue, take the concept one step further forward. They demonstrated that PLR can be performed in a completely non-invasive way using vascular tonometry. Vascular tonometry is a technology that measures the reflected waves transmitted to and from the heart after a suprasystolic clamp manoeuvre performed with a blood pressure cuff, in order to estimate the vascular tone of the patient. There are different systems able to look at the reflected waves and estimate the tone of the arterial tree, i.e. Pulsecor and SphygmoCor
[23-25]. The device used by the authors was the SphygmoCor, which enables PP to be measured non-invasively at the radial site. In this elegant study the authors demonstrated that PP measured using the SphygmoCor is as good as an invasive measurement at the femoral site as a predictor of fluid responsiveness during a PLR test. This is very important for two reasons. First, the authors demonstrated that PP measured at a peripheral site reflects very accurately aortic PP. It somehow proves that despite the inevitable generation of wave reflection in the arterial tree, peripheral measurement of arterial pressure provides an excellent estimate of aortic pressure (where wave reflection is minimal). Since aortic PP is the closest pressure to the heart (therefore directly linked to SV), this finding supports the use of peripheral arterial sampling for tracking SV with less-invasive PPA monitors. It basically means that variations in peripherally measured PP are very close estimates of variations in SV.

Second, the authors proposed a new totally non-invasive way to dynamically assess the circulation. Arterial PP can now be measured continuously at the level of the fingers, and we would not be surprised to see in the near future similar studies performed using these devices [26]. The study by Dufour et al. adds evidence that supports the physiological principle that PPA, whether invasive or non-invasive, is a powerful way of assessing changes in SV. PPA is a powerful tool to individualize fluid therapy in critically ill patients. We should not be too surprised about this since it is what Otto Frank said more than 100 years ago [1].

\section{References}

1. Frank O (1899) Die Grundform des arterielen Pulses erste Abhandlung: mathematische Analyse. Z Biol 37:483-526

2. Erlanger J, Hooker DR (1904) An experimental study of blood-pressure and of pulse-pressure in man. Johns Hopkins Hosp Rep 12:145-378

3. Wesseling KH, Jansen JR, Settels JJ, Schreuder JJ (1993) Computation of aortic flow from pressure in humans using a nonlinear, three-element model. J Appl Physiol 74:2566-2573

4. Jansen JR, Wesseling KH, Settels JJ, Schreuder JJ (1990) Continuous cardiac output monitoring by pulse contour during cardiac surgery. Eur Heart $\mathbf{J}$ 11(Suppl I):26-32

5. Rauch H, Müller M, Fleischer F, Bauer H, Martin E, Böttiger BW (2002) Pulse contour analysis versus thermodilution in cardiac surgery patients. Acta Anaesthesiol Scand 46:424-429
6. Hamilton TT, Huber LM, Jessen ME (2002) Pulse CO: a less-invasive method to monitor cardiac output from arterial pressure after cardiac surgery. Ann Thorac Surg 74:S1408-S1412

7. Scolletta S, Romano SM, Biagioli B, Capannini G, Giomarelli P (2005) Pressure recording analytical method (PRAM) for measurement of cardiac output during various haemodynamic states. Br J Anaesth 95:159-165

8. de Waal EE, Kalkman C, Rex S, Buhre W (2007) Validation of a new arterial pulse contour-based cardiac output device. Crit Care Med 35:1904-1909

9. Bland JM, Altman DG (1986) Statistical methods for assessing agreement between two methods of clinical measurement. Lancet $1: 307-310$

10. Critchley LA, Critchley JA (1999) A meta-analysis of studies using bias and precision statistics to compare cardiac output measurement techniques. J Clin Monit Comput 15:85-91
11. Cecconi M, Rhodes A, Poloniecki J, Della Rocca G, Grounds RM (2009) Bench-to-bedside review: the importance of the precision of the reference technique in method comparison studies - with specific reference to the measurement of cardiac output. Crit Care 13:201

12. Peyton PJ, Chong SW (2010) Minimally invasive measurement of cardiac output during surgery and critical care: a meta-analysis of accuracy and precision. Anesthesiology 113:1220-1235

13. Hamilton MA, Cecconi M, Rhodes A (2010) A systematic review and metaanalysis on the use of preemptive hemodynamic intervention to improve postoperative outcomes in moderate and high-risk surgical patients. Anesth Analg. doi: 10.1213/ANE.0b013e3181eeaae5

14. Rhodes A, Grounds RM (2005) New technologies for measuring cardiac output: the future? Curr Opin Crit Care 11:224-226 
15. Pinsky MR, Payen D (2005) Functional hemodynamic monitoring. Crit Care 9:566-572

16. Michard F (2005) Changes in arterial pressure during mechanical ventilation. Anesthesiology 103:419-428; (quiz 449-415)

17. Hofer CK, Muller SM, Furrer L, Klaghofer R, Genoni M, Zollinger A (2005) Stroke volume and pulse pressure variation for prediction of fluid responsiveness in patients undergoing off-pump coronary artery bypass grafting. Chest 128:848-854

18. Berkenstadt H, Friedman Z, Preisman S, Keidan I, Livingstone D, Perel A (2005) Pulse pressure and stroke volume variations during severe haemorrhage in ventilated dogs. $\mathrm{Br} \mathrm{J}$ Anaesth 94:721-726

19. Perel A (1998) Assessing fluid responsiveness by the systolic pressure variation in mechanically ventilated patients. Systolic pressure variation as a guide to fluid therapy in patients with sepsis-induced hypotension. Anesthesiology 89:1309-1310
20. De Backer D, Heenen S, Piagnerelli M, Koch M, Vincent JL (2005) Pulse pressure variations to predict fluid responsiveness: influence of tidal volume. Intensive Care Med 31:517-523

21. Teboul JL, Monnet X (2009) Detecting volume responsiveness and unresponsiveness in intensive care unit patients: two different problems, only one solution. Crit Care 13:175

22. Dufour N, Chemla D, Teboul JL, Monnet X, Richard C, Osman D (2011) Changes in pulse pressure following fluid loading: a comparison between aortic root (non-invasive tonometry) and femoral artery (invasive recordings). Intensive Care Med. doi: 10.1007/s00134-011-2154-z

23. Lowe A, Harrison W, El-Aklouk E, Ruygrok P, Al-Jumaily AM (2009) Non-invasive model-based estimation of aortic pulse pressure using suprasystolic brachial pressure waveforms. J Biomech 42:2111-2115
24. Mayer O Jr, Filipovsky J, Pesta M, Cifkova R, Dolejsova M, Simon J (2008) Synergistic effect of angiotensin II type 1 receptor and endothelial nitric oxide synthase gene polymorphisms on arterial stiffness. J Hum Hypertens 22:111-118

25. Wilkinson IB, Fuchs SA, Jansen IM, Spratt JC, Murray GD, Cockcroft JR, Webb DJ (1998) Reproducibility of pulse wave velocity and augmentation index measured by pulse wave analysis. J Hypertens 16:2079-2084

26. Eeftinck Schattenkerk DW, van

Lieshout JJ, van den Meiracker AH, Wesseling KR, Blanc S, Wieling W, van Montfrans GA, Settels JJ, Wesseling KH, Westerhof BE (2009) Nexfin noninvasive continuous blood pressure validated against Riva-Rocci/ Korotkoff. Am J Hypertens 22:378-383 